\title{
Dynamics of Passenger Demand and Transport Work in Croatian Public Road Traffic System
}

\author{
Tomislav Bubalo ${ }^{1,}$, Marijan Rajsman ${ }^{2}$, Tomislav Kukec ${ }^{3}$ \\ ${ }^{1}$ TB Consulting j.d.o.o., Zagreb, Croatia \\ ${ }^{2}$ Department of Road Transportation, Faculty of Transportation and Traffic Sciences, University of Zagreb, Zagreb, Croatia \\ ${ }^{3}$ Englmayer d.o.o., Zagreb, Croatia
}

Email address:

tomislav.bubalo@gmail.com (T. Bubalo),mrajsman@fpz.hr(M. Rajsman),tomislav.kukec11@gmail.com (T. Kukec)

${ }^{*}$ Corresponding author

\section{To cite this article:}

Tomislav Bubalo, Marijan Rajsman, Tomislav Kukec. Dynamics of Passenger Demand and Transport Work in Croatian Public Road Traffic System. American Journal of Traffic and Transportation Engineering. Vol. 5, No. 3, 2020, pp. 34-42. doi: 10.11648/j.ajtte.20200503.12

Received: June 12, 2020; Accepted: July 2, 2020; Published: August 17, 2020

\begin{abstract}
Passenger demand and transport work are the basic quantitative indicators of the effects achieved in public road passenger transport activities. The research is conducted to determine the need for managing the transport system and planning its further development. The aim of this paper was to determine the dynamics of development of these two sizes in the seventeen-year period from 2000 to 2016, and to use them to develop a prognostic trend model for the future period. Furthermore, the correlation analysis determined the relations between traffic and economic quantities, and the road transport system was compared by mathematical and statistical parameters with all other traffic systems of the Republic of Croatia, in order to determine its share and importance in the Croatian public transport system. Based on the analysis conducted for passenger demand, a future downward trend is projected. Future trends will be identified for transport work based on the developed trend model and correlations between transport and economic sizes. Furthermore, the road transport system accounts for the largest share of transport work and passenger demand in the Croatian public transport system.
\end{abstract}

Keywords: Croatian Public Road Traffic System, Prognostic Trend Model, Passenger Demand, Transport Work

\section{Introduction}

In this paper, the main subject of research is the realized transport work and passenger demand in the Croatian transport system, that is, the dynamics of their realized values through the time interval from 2000 to 2016. The transport system can be defined as a set of conveyor systems in any particular area over time settled the demand for transport services in passenger and freight in both the public and for its own needs as well as individual traffic. Passenger and freight demand by size and structure are dimensioned by other subsystems of a particular transport system.

Transport work represents the realized transport performance of carriers in the public road transport system. The number of passengers carried and passenger transport work are the basic quantitative indicators of the dynamics of the development of public road passenger transport in the transport system. Passenger demand is crucial for guiding and determining transport policy, as it determines the development of the transport system primarily through the degree of utilization of transport infrastructure and means of transport and transport work.

The first goal of the paper is to perform an analysis that will determine the prognostic trend models of these two sizes on the basis of current trends. Similarly, the correlation between economic and traffic quantities is examined and regularities and correlations of traffic with the most significant economic quantities are determined. Furthermore, the demand and realized transport work in the road transport system is compared with other transport systems in the Croatian transport system. The second objective of the paper is to investigate and compare trends in passenger demand and transport work in public passenger transport in the Republic of Croatia. The third objective is to investigate the relations between passenger demand and transport work and trends in 
their movement in the Republic of Croatia, in order to find out about the dynamics and in particular the possible regularity of development.

The scientific contribution of the work is to understand the dynamics of passenger demand and transport work in the public road transport system. The purpose of the research conducted in this way stems from the need to manage the transport system and to plan its process for its further development. Applying scientific methods of analysis and synthesis, compilation, methods of mathematical statistics (especially arithmetic mean, standard deviation, coefficient of variability and average annual rate of change), one can understand the dynamics of passenger demand and transport work in Croatian public road passenger traffic in the studied period. All trends are represented graphically by a linear trend model. With the appropriate value of the coefficient of determination, the level of significance of the model can be determined.

\section{Background}

The domestic scientific and professional literature mainly analyzes the passenger demand, whose properties and values are mostly observed for the purpose of modeling the development of the transport system. The topic of passenger demand in the transport system is research with a detailed analysis of its structure and dynamics, where he studies the movements and realized values of transported passengers for the period from the 1960 s to 1996 , and provides a prognostic view of the development of Croatian public transport, passenger intercity transport [1]. The model for the development of the transport system of central Croatia is research in doctoral dissertation by investigating the relationship between transport and economic variables [2].

The problem of studying the dynamics of development and trends in demand passenger transport in the system of public bus transportation in the City of Zagreb and the possibility of scientific application of mathematical models for the management and optimization of the transport process the authors describe in research [3]. The purpose of the study is to predict passenger demand in the public passenger transport system for the purpose of managing public urban transport. Next studies investigate the dynamics and possibilities of modeling the development of passenger traffic demand in the Zagreb suburban rail system and inland rail passenger traffic in the Republic of Croatia [4][5]. Also conduct research related to the structure of traffic relations in the Croatian road system freight transport [6]. The modeling of passenger demand and the transportation work of road haulage companies and the optimization of transport processes and cost structure are addressed by the research [7].

In the world scientific and professional literature, research where is presented an integrated system of discrete passenger choice for predicting travel demand in suburban areas of large cities based on travel selection activities and the schedule of particular economic activities [8]. The author's research presents and investigates user behavior when choosing travel on different types of public transportation corridors where a dynamic multi-passenger flow analysis model based on the theory of dynamic equilibrium is proposed [9]. Next research explores the problem of large variations in passenger demand. This paper presents a model for improving the system performance by adopting a dynamic bus schedule. The model simulates the flow of passengers at each stop and the movement of buses along the route [10].

The interdependence of transport infrastructure and travel demand is explored in study [11]. Well-functioning transport markets should enable traffic supply to meet traffic demand to meet traffic mobility needs. The author notes that an economic system that includes a number of activities located in different areas of transport creates mobility that the transport system must support. Next study analyzing the factors that explain travel demand in local public transport along with variables related to traditional economic factors and mobility has been presented in a study [12]. The productivity of transport services in public urban transport and its impact on traffic demand have been studied in research [13][14]. In their studies, the authors present the cost structure and transport work of road passenger transport companies. Next study provides a literature review of the factors that influence the demand for public transport services and summarizes the results [15]. The study provides an overview of the literature specifically from an operational standpoint to assist public transport operators, decision makers and decision-makers in research based on demand for public transportation services and those who understand the factors that shape it.

\section{Passenger Demand in Croatian Public Road Passenger Transport}

Passenger demand is the basic size by which the structure of the superstructure and the transport capacity of the fleet are measured. The optimum capacity is in line with the level and structure of demand for transport services, and directly affects the business performance of road transport companies. The purpose of a road passenger transport undertaking is to meet the demand for transport services in the passenger transport market.

Passenger demand is crucial for determining and managing transport policy, and is also a fundamental factor that dimensions the level of development of the transport system and, consequently, the degree of utilization, above all of its technical stratum, ie transport infrastructure and means of transport [16][17]. Studying transport demand (ie the number of passengers transported and transport work performed), for example at national level over a period of time, leads to conclusions about the dynamics of road passenger transport, and based on the conclusions reached, different political and economic measures can influence the desired development of public road transport system.

In research on passenger demand in public road passenger 
transport, Malić (1999) focused on the needs of domestic transport. The reasons why travelers choose to travel are different: work, housing and care, family and friendship, education, culture, sports, politics and profession, and holiday and recreational activities. Likewise, Malić (1999) states that the level and directions of travel are influenced by the following factors: property status, monthly household income and car ownership in the household. It also highlights the demographic characteristics of the household: household size (number of members), household age (age of members), and household gender characteristics (male and female members).

In the case of interurban passenger road transport, spatial factors are also important: distance of the transport stop, distance to the place of employment, school, municipal center or city. Finally, there are very important qualitative characteristics for long-distance demand: the frequency of departures (frequency), the spatial availability of stops, the price and the convenience of transportation, investigated authors in the study [18]. During the transport process, passengers are transported on certain transport routes and transport work is carried out. The passenger transport unit of work is the passenger kilometer [pkm], that is, the work accomplished by transporting one passenger over a distance of one kilometer. In addition to passenger demand as measured by the number of passengers carried, transport work is the most significant quantitative indicator of a carrier's business. Transport work depends on: the transport capacities of the transport companies, the passenger demand and the distances at which the passenger transport process is carried out [19].

\section{Transport Work in Croatian Public Road Passenger Transport}

Solving the transport problem on the transport network provides an optimal organizational scheme of transport between a number of road haulage companies and demand centers and bus stops. The road haulage company has its own capacity and the demand center is the level of demand. Transport links between these centers or hubs have different unit transport rates, and the solution to this problem is to achieve the best possible solution for transport between nodes. In order for the solution to be optimal, the following two conditions must be satisfied, the first condition being that demand for the network must be satisfied, and the second condition being that it is done with minimal transport costs [20].

In determining the optimal solution to a transport problem without the use of software tools, the initial solution must be found and then determined optimally. Methods such as: northwest corner, least cost, and Vogel approximation methods are used to determine the initial solution. The determination of the optimal solution is carried out by the use of the relative cost method or the method of jumping from stone to stone [21].

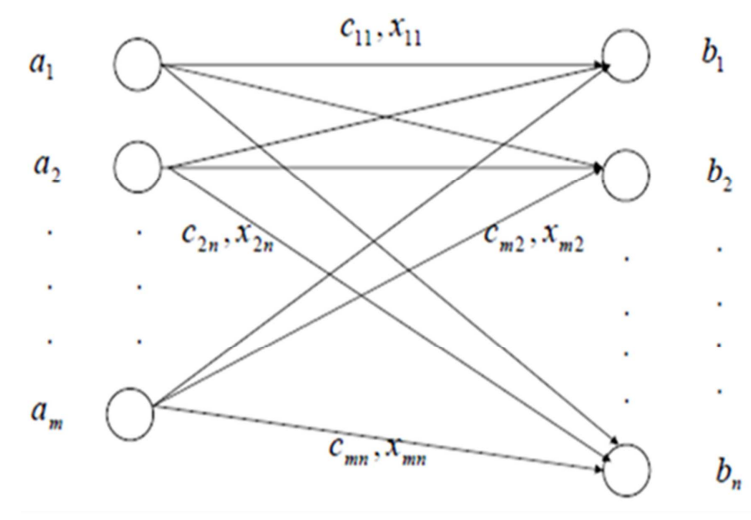

Figure 1. Schematic representation of transport work.

Figure 1 shows an organization chart according to which transport between different starting points $\left(a_{m}\right)$ and destination $\left(b_{n}\right)$ takes place according to a pre-determined timetable. $C_{i j}$ denotes the unit cost from the starting point $i$ and to the destination $j$, and $X_{i j}$ transported the number of passengers from the starting point $i$ and to the destination $j$. The location of multiple capacities is a problem of finding the most suitable locations for a number of bus stops of different capacities, which can be accommodated in a number of locations. As with transport between nodes, a solution is sought that will give the least transport cost. The problem is solved by solving for each possible combination of bus stops to a group of possible locations an appropriate transport problem, thus providing for each such combination an optimal transport solution for which the value of the total transport costs is minimal. Comparison of optimal solutions of different combinations of bus stops to a group of possible locations gives the location that is most favorable in terms of transportation costs.

In order to write down the problem of the shortest path mathematically, it is first necessary to set up a network, by which it is intended to send a certain number of passengers from node 1 , to node $m$ at the lowest cost $b_{1}=1, b_{m}=-1, b_{i}=$ 0 for $i \neq 1$ or $m$.

Then the mathematical model reads:

1. $c_{i j}$ - the cost of transporting passengers from the starting point $i$ and to their destination $j$

2. $x_{i j}$ - number of passengers to be transported from the starting point $i$ and the destination $j$

3. $k$ - the shortest path

Function:

$$
\min \mathrm{F}=\sum_{i=1}^{m} \sum_{j=1}^{m} c_{i j} x_{i j}
$$

Limitations:

$$
\begin{gathered}
\sum_{i=1}^{m} x i j-\sum_{k=1}^{m} x k i=1 \text { if } i=1,0 \text { if } i \neq 1 \text { or } m,-1 \\
\text { for } i=m \\
\mathrm{X}_{i j} \geq 0, i, j=1, \ldots, m
\end{gathered}
$$

The model described can be applied for the calculation of transport work in transport companies. Since the implementation of the central information system and the exchange of essential traffic data among the operators creates 
a database for processing, the purpose of which is to optimally manage the fleet. Better utilization of vehicle capacity, reduction of vehicle and driver organization time, and faster recruiting of vehicles on lines leads to a significant reduction in the cost of the overall transport process [22][23].

The allocation of indirect costs ranges from the highest levels to the lowest levels of the calculation vertical hierarchy. The calculation was made when all indirect costs were allocated to profit. Independent fixed cost performance is not included in the final shaping of the company's profits. Company costs are divided into fixed and variable costs, with variable costs being divided into primary and secondary components [24]:

$$
\mathrm{C}_{\mathrm{t}}=\mathrm{C}_{\mathrm{ft}}+\mathrm{C}_{\mathrm{vt}}=\mathrm{C}_{\mathrm{ft}}+\mathrm{C}_{\mathrm{vt}(\mathrm{p})}+\mathrm{C}_{\mathrm{vt}(\mathrm{s})}
$$

where is:

$C_{t}$ - cost of cost centre (company)

$C_{f t}$ - fixed cost of cost centre

$C_{v t}$ - variable cost of cost centre

$C_{v t(p)}$ - variable primary cost of cost centre

$C_{v t(s)}$ - variable secondary cost of cost centre

Variable secondary costs are the sum of isolated variable costs that come from an operating center based on the relative performance of the transportation service, and the costs of the company can be calculated as follows:

$$
C_{t}=C_{f t}+C_{v t(p)+} \sum_{i=1}^{n}\left(C_{v i} \frac{P_{k i}}{P_{i}}\right)
$$

where is:

$C_{v i}$ - variable cost of service cost centre

$P_{i-}$ performance of service cost centre

$P_{k i}$ - performance consumption of cost centre

According to the proposed methodology, formulas for the final setting of fixed and variable costs that would be taken into account fleet optimizations have been derived and should be used in conjunction with other transport service performance such as service time and time savings factor, operating center cost (technology and transport management). From this, we get the final formulas for the cost of transport work as follows:

$$
C_{j}=C_{j(d)}+\frac{T_{j}}{\sum_{j=1}^{m} T_{j}} \sum_{k=1}^{n} C_{f t}+\sum_{i=1}^{n} C_{v i} \frac{P_{j i}}{P_{i}}
$$

where is:

$P_{j i}$ - performace consumption on profit object

$T_{j^{-}}$duration or transport service time of profit object

$$
C_{J}=\frac{C_{f t}}{\sum_{j=1}^{m} T_{j}} T_{j}+\frac{C_{v t}}{\sum_{j=1}^{m} D_{j}} D_{j}+C_{j(t)}
$$

where is:

$D_{j}$ - transport performance of profit object

$C_{j(t)}$ - dedicated cost of profit object

It is important to emphasize now that all the costs of the company have been specified and when all relevant information is available, it is possible to finally set up an algorithm for the costs of the transport process and to optimize the use of the company fleet [25]. In the future, advance and travel information for passengers will be increasingly relevant to the choice of travel and the choice of carrier by passengers. With the establishment of an information system, transport management will make it technologically easier to decide on vehicle use, capacity utilization, cost reduction and manipulation time, which ultimately leads to an increase in the competitiveness of enterprises [26]. Based on the above data, costs can be calculated on a monthly, quarterly and annual basis, depending on the company's business growth projection. The final setup is shown in Table 1, and the algorithm for calculating transport work is as follows:

\begin{tabular}{|c|c|c|c|}
\hline \multirow{2}{*}{ CALCULATION OBJECT } & \multirow{2}{*}{ PRIMARY COST ITEMS } & \multicolumn{2}{|l|}{ COST DRIVER } \\
\hline & & INDICATOR & DIMENSION \\
\hline CENTRAL MANAGEMENT(CM) & $\begin{array}{l}\text { all cost items which can not be connected to cost of the } \\
\text { other objects }\end{array}$ & ------- & ----- \\
\hline $\begin{array}{l}\text { TECHNOLOGY MANAGEMENT } \\
\text { (TE) }\end{array}$ & semi-fixed: personnel costs & $\begin{array}{l}\text { Working time } \\
\text { (wt) }\end{array}$ & Man/hour \\
\hline $\begin{array}{l}\text { TRANSPORT MANAGEMENT } \\
\text { (TR) }\end{array}$ & semi-fixed: personnel costs & $\begin{array}{l}\text { Working time } \\
\text { (wt) }\end{array}$ & Man/hour \\
\hline VEHICLE (VE) & $\begin{array}{l}\text { semi-fixed: leasing costs, depreciation } \\
\text { (own vehicles), insurances and taxes } \\
\text { variable: material costs including outsourced } \\
\text { maintenance }\end{array}$ & $\begin{array}{l}\text { Vehicle running } \\
\text { (vr) }\end{array}$ & Kilometre \\
\hline $\begin{array}{l}\text { DRIVER (DR) } \\
\text { TRANSPORT SERVICE (TS) }\end{array}$ & $\begin{array}{l}\text { semi-fixed: wage-related personnel costs } \\
\text { variable: bonus or performance related personnel costs } \\
\text { direct costs: dedicated (tolls charges, etc...) } \\
\text { fuel costs(where appropriate) }\end{array}$ & $\begin{array}{l}\text { Working time } \\
\text { (wt) }\end{array}$ & Man/hour \\
\hline
\end{tabular}

$$
\begin{array}{r}
C_{j}=C_{j(d)}+\frac{T_{j}}{\sum_{j=1}^{m} T_{j}}\left(C_{C M}+C_{(f) M A}\right)+\frac{W t_{j D R y}}{W t_{D R Y}}\left(C_{D R Y}+C_{T E} \frac{W t_{D R y T E}}{W t_{T E}}\right)+\frac{V r_{j V E x}}{V r_{V E x}}\left(C_{V E x}+\frac{m t_{V E x M A}}{m t_{M A}}\left(C_{V M A}+C_{T E} \frac{W t_{M A, T E}}{W t_{T E}}\right)+\right. \\
\left.C_{T E} \frac{W t_{V E x T E}}{W t_{T E}}\right)+C_{T R} \frac{W t_{j T R}}{W t_{T R}}
\end{array}
$$

Table 1. Costs structure of costs centres and profit objects. 


\subsection{Dynamics of Passenger Demand and Transport Work in CROATIAN Public Road Passenger Transport}

The dynamics of passenger demand in the Croatian public road transport system is analyzed for the period between 2000 and 2016. In addition, the trends of passenger demand and transport work are investigated and the corresponding mathematical prognostic model is calculated. Furthermore, in order to reach as clear conclusions as possible about the dynamics of the observed quantities over the studied time period, dynamic statistical measures are used: arithmetic mean, standard deviation of the sample, coefficient of variability, average annual rate of change. Data on the number of passengers carried and passenger transport work performed, expressed in passenger kilometers [PKM], were taken from (Rajsman, 2005). Traffic demand, and therefore transport work, are stochastic in nature, so it is necessary to use mathematical statistics and probability theory methods in modeling, with the establishment of a trend in the development of traffic magnitude. The trend represents a tendency for the development of traffic magnitude in time and is a function of time.

Transport modeling has a significant role to play in the increasingly complex decision-making processes, especially when it comes to modeling traffic development. Given the dynamic of changes in the economic and transport system, analytical methods, which detect changes over a shorter period of time, are preferable for traffic analysis, so that the subject matter and results of research and modeling are more focused [27]. Furthermore, in addition to dynamic statistical benchmarks, in this paper, on the basis of established trends, models of simple linear regression (regression models) should be developed as a basis for planning the further development of the public road passenger transport system.

The regression model developed in this paper determines the value of the dependent variable $Y$, which, due to the stochasticity of the system, is not uniquely determined for the given value of the independent variable $X$, as stated in [28]:

$$
Y=f(x)+u
$$

where is:

$f(x)$ - functional (deterministic) component

$u$ - a stochastic variable that represents non-systematic effects on the dependent variable

The significance of the prognostic trend of the simple linear regression model is verified through the value of the coefficient of determination $\mathrm{R}^{2}$. The coefficient of determination according to (Šošić and Serdar, 2002) can take values between 0 and 1 . The height of the coefficient of determination indicates the representativeness of the model, so that the model is more representative the $\mathrm{R}^{2}$ closer to 1 . According to the Chadock scale, which classifies the value of the coefficients of determination, if that value is 0.64 or more between the two variables is solid, and the model is significant.

According to Table 2, a decrease in the number of passengers carried at the end of the analyzed period can be observed. The arithmetic mean of the passengers carried in the observed period is 59669 passengers, with a standard deviation value of 6.060 , and a coefficient of variability of $10.16 \%$. The relative annual rate of change is a decrease of $1.72 \%$ of passengers carried. It is very important to mention here that data on road passenger transport since 2015 only includes public regular transport and relates to the work of business entities engaged in public passenger transport.

Until 2014 and after 2015, the statistical survey includes active business entities with more than 10 employees classified in area $\mathrm{H}$ according to the National Classification of Activities (NKD) 2007, class 49.39. Other passenger land transport in the statistical business register of the Central Bureau of Statistics and business entities with fewer than 10 employees who were authorized to perform public passenger transport on a regular service. That is, the data included occasional passenger transport [29]. This means that data analysis should take into account the fact that in 2015 public occasional road passenger transport was excluded.

Table 2. Passenger demand in Croatian public road passenger transport.

\begin{tabular}{ll}
\hline Year & Number of carried passengers \\
\hline 2000 & 66.556 \\
2001 & 67.553 \\
2002 & 65.852 \\
2003 & 65.413 \\
2004 & 64.768 \\
2005 & 64.859 \\
2006 & 63.576 \\
2007 & 63.144 \\
2008 & 62.064 \\
2009 & 58.493 \\
2010 & 56.419 \\
2011 & 52.561 \\
2012 & 52.293 \\
2013 & 54.292 \\
2014 & 54.000 \\
2015 & 52.126 \\
2016 & 50.400 \\
Arithmetic mean (X) & 59.669 \\
Standard deviation (s) & 6.060 \\
Coefficient of variability (V) & $10,16 \%$ \\
Average annual rate of change (S) & $-1,72 \%$ \\
\hline
\end{tabular}

The linear trend model of passenger demand dynamics (10) in the future predicts a further decrease in the observed value, with a coefficient of determination (11) of $R^{2}=0.92$, and in this case the statistical model shown is significant, with a confidence level of $\mathrm{p}<0.01$.

$$
\begin{gathered}
Y=-1151,3 x+70031 \\
R^{2}=0,92
\end{gathered}
$$

Figure 2 shows the data on the dynamics of transported passengers in Croatian public road passenger transport in the period 2000-2016. Figure 2 shows a slight increase in passengers carried at the very beginning of the observed period in 2001 compared to 2000, and then from 2002 there is a trend of slight decline and stagnation until 2008. From 
2009 to 2012, there is a trend of even more significant decline in passenger demand compared to the previous period. The reason for this may be sought in the coming economic recession and in the transport market in the Croatian transport system. In 2012, the trend of significant decrease in passenger demand stopped, and for the first time in the observed period a significant increase in the number of passengers carried in 2013 appears. After that, the three-year trend of declining passenger demand continues until the end of the observed period.

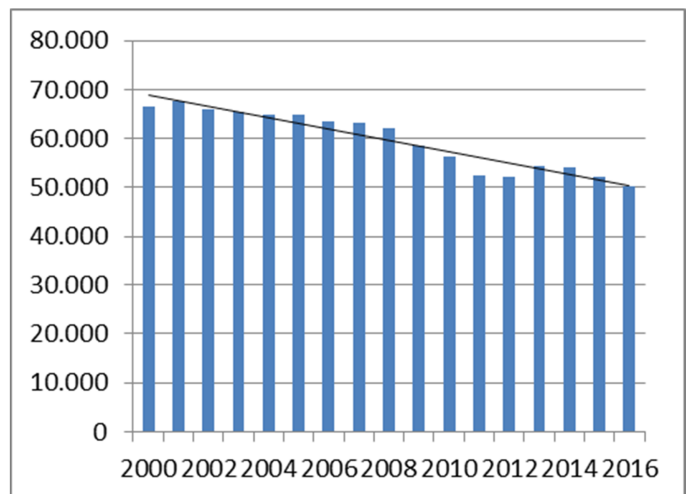

Figure 2. Dynamics of passenger demand in public road passenger transport in the Republic of Croatia.

The realized passenger transport work in the analyzed time period is shown in Table 3. The arithmetic mean of the observed sample is 3515651 [pkm]. While the standard deviation of the sample is 238819 , with a value of the coefficient of variability of $\mathrm{V}=6.79 \%$. If this data is compared with the variability of the sample of passenger demand in the observed period, it is concluded that the values of passenger transport work vary less than the value of the number of passengers carried, since the coefficient of variability in the total road passenger demand is $10.16 \%$.

Table 3. Passenger transport work in Croatian public road transport in the period from 2000 to 2016

\begin{tabular}{ll}
\hline Year & Passenger kilometers [pkm] \\
\hline 2000 & $3.331,147$ \\
2001 & $3.477,757$ \\
2002 & $3.557,693$ \\
2003 & $3.716,850$ \\
2004 & $3.390,253$ \\
2005 & $3.403,469$ \\
2006 & $3.537,056$ \\
2007 & $3.807,980$ \\
2008 & $4.093,489$ \\
2009 & $3.437,996$ \\
2010 & $3.284,418$ \\
2011 & $3.145,021$ \\
2012 & $3.249,078$ \\
2013 & $3.506,977$ \\
2014 & $3.647,879$ \\
2015 & $3.377,000$ \\
2016 & $3.802,000$ \\
Arithmetic mean (X) & $3.515,651$ \\
Standard deviation (s) & 238.819 \\
Coefficient of variability (V) & $6,79 \%$ \\
Average annual rate of change (S) & $0,829 \%$ \\
\hline
\end{tabular}

The average annual rate of change in passenger transport work is $+0.83 \%$, while the value of the average annual rate of change in passenger demand records an annual average decrease of $1.61 \%$. Based on this, it can be concluded that despite the fall in passenger demand, there has been a positive increase in the realized passenger transport work.

The dynamics of realized passenger transport work in the public road transport system in the observed 17-year period is also shown in Figure 3. Figure 3 shows the trend of threeyear growth of realized passenger work from 2001 to 2003. After that comes a two-year period of decline and stagnation. In order for the trend of constant growth of transport work to emerge from 2006 to 2008, the largest transport work in 2008 was achieved. From 2009 to 2011, due to the economic recession, there is a downward trend, which was especially emphasized in 2011. In the three-year period from 2012 to 2014, there is a trend of steady growth in transport work. In 2015, due to the already mentioned change in the way of keeping statistics, there is no accurate data on the realized transport work, but in the last observed year these values rise to a value higher than the one from 2014.

Based on the existing trend model (12), a very slight decrease in this value can be predicted, but according to the coefficient of determination $\mathrm{R}^{2}$ (13) for the existing model, the reliability is very low and the model made is not significant. Based on the statistics on the dynamics of movements, these values cannot be predicted with certainty for future movements.

$$
\begin{gathered}
\mathrm{Y}=828,36 \mathrm{x}+4 \mathrm{E}+06 \\
\mathrm{R}^{2}=0,0003
\end{gathered}
$$

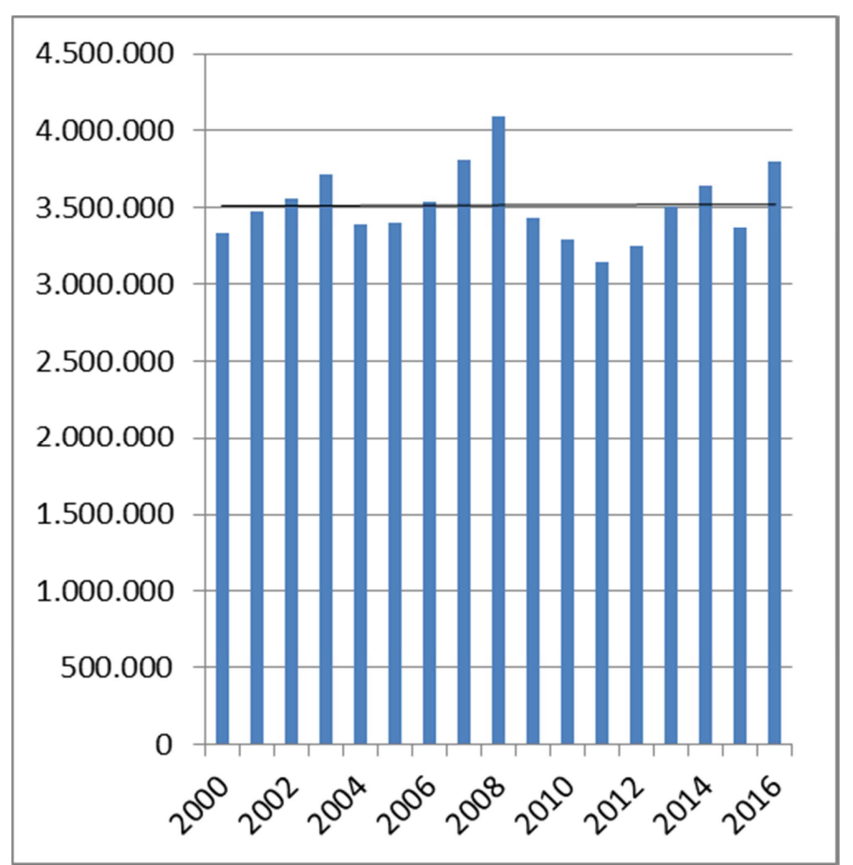

Figure 3. Dynamics of passenger transport work in public road transport of the Republic of Croatia from 2000 to 2016. 


\subsection{Relation Between Passenger Demand and Transport Work with the Most Significant Economic Sizes}

In order to fully analyze the dynamics of passenger demand and transport work, it is necessary to include the dynamics of economic indicators in the analysis, since the road transport system is an integral part of the overall economic system. Data on realized economic indicators for the observed period are taken from [30].

In this paper, the following economic indicators are taken as: gross domestic product (GDP), average net wage in the Republic of Croatia and the number of registered road motor vehicles. The relationship between economic magnitudes and passenger demand and transport work will be investigated using a correlation uterus into which Pearson's correlation coefficients are entered (Table 4).

Pearson's correlation coefficient is based on a comparison of the real impact of the observed variables on each other versus the maximum possible influence of the two variables. The correlation can be positive and negative. If both variables fall or the correlation is positive, and if the fall of one variable causes the other to rise, the correlation is negative. In Table 4, the correlation coefficients, which represent a solid bond, are indicated in red. The values of the correlation coefficient $r$ are as follows:

1) $0,00-0,50 \rightarrow$ Poor connectivity

2) $0,50-0,80 \rightarrow$ Medium connectivity

3) $0,80-1 \rightarrow$ Strong connectivity

4) $1-1+\rightarrow$ Full connectivity

Table 4. Correlation matrix of transport and economic variables of the Republic of Croatia in the period 2000 to 2016.

\begin{tabular}{|c|c|c|c|c|c|}
\hline & $\begin{array}{l}\text { Passenger } \\
\text { demand }\end{array}$ & Transport work & GDP & $\begin{array}{l}\text { Average net } \\
\text { wage }\end{array}$ & $\begin{array}{l}\text { Number of registered } \\
\text { road motor vehicles }\end{array}$ \\
\hline Passenger demand & $1,000 *$ & 0,183 & $-0,771$ & $-0.914 * *$ & $-0,735$ \\
\hline Transport work & 0,183 & $1,000 *$ & 0,179 & $-0,028$ & 0,186 \\
\hline GDP & $-0,771$ & 0,179 & $1,000^{*}$ & $0,955 * *$ & $0,985 * *$ \\
\hline Average net wage & $-0,914 * *$ & $-0,028$ & $0,955 * *$ & $1,000 *$ & $0,930 * *$ \\
\hline Number of registered road motor vehicles & $-0,735$ & 0,186 & $0,985 * *$ & $0,930 * *$ & $1,000^{*}$ \\
\hline
\end{tabular}

According to the data in the correlation matrix (Table 4), it is evident that a strong connectivity between travel demand and individual economic indicators exists only between the average net wage paid, and this relationship is inversely proportional. There is also a strong positive correlation between economic indicators. The gross domestic product of the Republic of Croatia (GDP) and the number of registered passenger cars are with the variable passenger demand in inversely proportional correlation of medium connectivity.

On the basis of these data, it can be concluded that economic indicators have a strong influence on each other in proportion, and with the change of one of the variables the other two change. Travel demand falls with the increase in the average net wage paid. This leads to the conclusion that the higher the purchasing power of the population, the lower the demand for public transport. The respective population decides to transport with their own means of transport. Furthermore, between passenger demand and GDP, and net wages paid, there is a relationship of medium strength of negative correlation, indicating that also with positive developments in GDP and net wages, passenger demand is decreasing (inversely proportional to the relationship).

Regarding transport work, the linear correlation coefficients show that there is no correlation between it and the other variables studied. This leads to the conclusion that the transport work, that is, the transport performance of Croatian carriers in the public road transport system, takes on its value regardless of the value of the most important economic indicators of economic development and purchasing power of the population, and that it depends on the management of the transport company.

\section{Analysis of the Dynamics of Passenger Demand and Transport Work in the Transport System of the Republic of Croatia}

This chapter compares the dynamics of passenger demand and the passenger transport operation of transport systems within the Croatian transport system in order to determine the role of the road transport system in public passenger transport of the Republic of Croatia.

\subsection{Structure of Passenger Demand in the Transport System of the Republic of Croatia}

Figure 4 shows the dynamics of passenger demand for all transport systems in the Croatian transport system from 2000 to 2016. From Figure 4, it can be concluded: the dominant role of the road system in meeting passenger demand, with a relatively short period from 2007 to 2010 when the rail system reached the road level in 2007 and carried the largest number of passengers in public passenger traffic in the next three years. After 2010, by the end of the studied period, there has been a steady downward trend in the share of the railway transport system in meeting passenger demand, but it is still convincingly second behind road transport during this period.

The maritime transport system, with its share (in absolute and relative terms) in the whole period, is in third place behind the road and rail systems, while the air transport has the smallest share in meeting passenger demand. An additional explanation for the increased share of the railway system in meeting the passenger demand in the studied 
period is as follows: from the third quarter of 2006 free tickets (students, students, pensioners, social cards) through the Subsidy Contract for the inclusion of the railway in the total transportation of passengers are included public transit system in Zagreb [31]. This has led to an increase in rail transport demand, and as early as 2007 the number of passengers transported by road and rail has equalized.

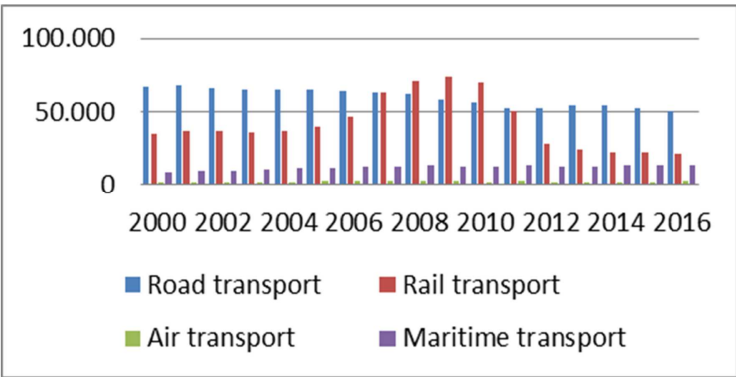

Figure 4. Dynamics of demand for transport services in Croatian public passenger transport from 2000 to 2016.

Subsequently, in the next three years, the trend of more passengers carried by rail than by road appeared, and the highest ratio between the number of passengers carried in favor of the railway was recorded in 2009. Since 1. July 2011 subsidies for free transport in the City of Zagreb have been abolished, resulting in a direct decrease in passenger demand in the rail transport system. According to the performed mathematical and statistical analysis, the highest coefficient of variability was recorded in railway transport $(42.66 \%)$, while in other transport systems this coefficient was lower than in road transport (19.29\% in air and $13.63 \%$ in water). The average annual rate of change is negative for the most represented transport systems $(1.72 \%$ in the road and $3.21 \%$ in the railway), while in the air and maritime transport it is positive and amounts to $3.33 \%$ in the maritime and $4.30 \%$ in the air transport system.

\subsection{Structure of Passenger Transport Work Performed in the Transport System of the Republic of Croatia}

The dynamics of passenger transport work in the Croatian transport system throughout the observed period is shown in Figure 5. From the figure it is evident that throughout the period the largest transport work is achieved in the road transport system (throughout the observed period twice or more than in relation to transport work in air traffic). It is interesting to note that in the period from 2012 to 2014, only the road transport system recorded a trend of growth in passenger transport work.

According to the mathematical and statistical analysis, the smallest deviations of the realized passenger transport work from the mean value are $6.79 \%$ for the road transport system, while this value is between 20.5 and $26.5 \%$ for other transport systems. If we look at the average annual rate of change in passenger transport work as part of an analysis of its dynamics, only the average decrease in the realized transport effects $(-2.49 \%)$ is present in rail transport. Other transport systems have an average increase in passenger transport work performed (the lowest in road transport $0.83 \%$ and the highest in air transport 5.11\%).

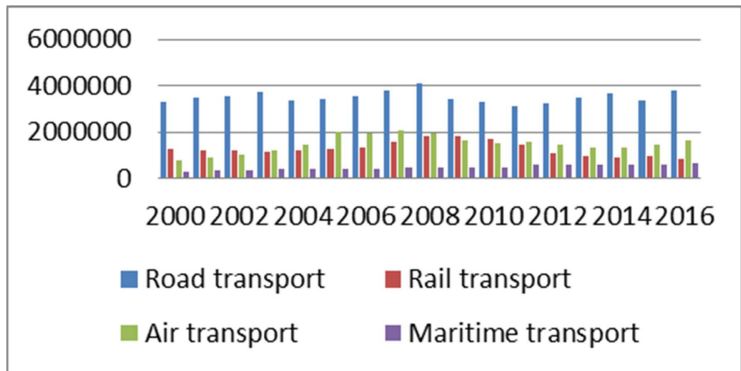

Figure 5. Dynamics of passenger transport work in public Croatian passenger traffic from 2000 to 2016.

\section{Conclusion}

In the road transport system, most of the passenger demand in the Croatian transport system is settled. During the observed period, a statistically significant trend of decreasing passenger demand in the road transport system was detected. According to the correlation matrix, it is found that passenger demand is inversely proportional to the average net wage paid.

In the total passenger transport work in the observed period in the Croatian transport system, the road system accounts for the largest share of about $65 \%$. Despite the negative average annual rate of total passenger demand, the achieved passenger transport work in the road transport system recorded an average annual growth rate, which can be explained by the adaptability of road carriers in the transport services market. For the period of time observed, the statistical trend model is not significant, that is, no significant trend was observed, and its further trends in the future period cannot be predicted. Likewise, the correlation matrix indicates the disconnect between transport work with the analyzed economic indicators and passenger demand, which leads to the conclusion that management is crucial.

It should be added that the economic demand in the country is the biggest influence on the passenger demand, therefore the state can be more influenced by the measures of transport and economic policy, while the transport companies are more influenced by the transport companies themselves, which economically operate and adapt the existing transport capacities to the dynamics and they adjust the structure of passenger demand to movements in the transport services market.

\section{References}

[1] Malić, Adolf. 1999. "Transport demand in the long-distance road passenger line traffic.” Edition, Dr. Feletar Zagreb, pp. 179-180.

[2] Rajsman, Marijan. 2005. "Model of Development of the Traffic System of Central Croatia," Doctoral dissertation. Faculty of Transportation and Traffic Sciences, University of Zagreb, Croatia. 
[3] Rajsman, Marijan; Tolić, Ivan and Rajsman, Bruno. 2013. "Development of Trend Model of the Passenger Demand for Public Bus Transport." Journal of traffic and logistics engineering, 1 (2): 218-221.

[4] Rajsman, Marijan; Ratković, Dražen and Biškupić Grgačević, Helena. 2015."The Dynamic of the Suburban Railway Passenger Transport in the Traffic System of the City of Zagreb." Journal of Traffic and Logistic Engineering 3 (1): 15 .

[5] Rajsman, Marijan. 2015. "Transport Demand as a Fundamental Factorin Modelling Transpoort System Development." International Conference on Transportation Sciences and Technologies- ICTST 2015, Zhuhai, China.

[6] Rajsman, Marijan; Luburić, Grgo and Muhin, Matija. 2017. "Dynamics and Trends of the Development of Transport Relations in Road Freight Traffic.” Journal Technical Gazette 24 (2): 635-642.

[7] Jurčević, Marinko; Bubalo, Tomislav and Mandžuka, Bia. 2018. "Influence of Costs on the Optimization of Transport Routes (case study)." Journal Econviews: Review of Contemporary Entrepreneurship, Business, and Economic Issues 31 (1): 65-73.

[8] Bowman, John and Ben-Akiva, Moshe. 2001. "Activity based disaggregate travel demand model system with activity schedules." Transportation Research Part A: Policy and Practice. 35 (1): 1-28.

[9] Di, Di and Yang, Dongyuan,. 2015. "Dynamic Traffic Analysis Model of Multiple Passengers for Urban Public Transport Corridor." Advances in Mechanical Engineering. 7 (11): 1-10.

[10] Marwah, Bar; Parti, Raman and Ram, Sayee. 2010. "Dynamic Scheduling of Buses on a Corridor and Sensitivity Analysis for Generation of Primary Bus Routes." Indian Institute of Technology, Department of Transportation Engineering, Kanpur.

[11] Rodrigue, Jean-Paul. 2017. "The Supply and Demand for Transportation." The Geography of Transport Systems-Fourth edition. New York: Routledge, 440 pages. ISBN 9781138669574 .

[12] Albalate, Daniel and Bel Germa. 2010. "What shapes local public transportation in Europe? Economics, mobility institutions, and geography." Transportation Research Part E: Logistics and Transportation Review, 46 (5): 775-790.

[13] Barnum, Darold; McNeil, Sue and Hart, Jonathon. 2007. "Comparing the Efficiency of Public Transportation Subunits Using Data Envelopment Analysis." J. Public Transportation, 10 (1): 1-16.

[14] De Borger, Bruno and Kerstens, Karen. 2006. "The Performance of Bus Transit Operators." Document de travail du LEM, 1 (3) 1-21.

[15] Polat, Cihat. 2012. "The Demand Determinants for Urban Public Transport Services: A Review of the Literature" Journal of Applied Sciences, 12 (1): 1211-1231.

[16] Padjen, Juraj. 2002. "Transport Demand and Shape of the
Space of the Croatian State - Important Determinants of the Croatian Traffic Policy." Roads and Bridges 3 (4): 71-80.

[17] Statistical Reports. 2017. Transport and Communication/Statistical Yearbook for the period 20002016. Croatian Bureau of Statistics. Zagreb, 2018.

[18] Bubalo, Tomislav; Jurčević, Marinko and Steiner, Sanja. 2017. "Analysis and Strategic Planning of Bus Passenger Transport with Reference to the Status of Croatia." In Proceedings of the 25th International Symposium on Electronics in Transport (ISEP). Ljubljana, (Slovenia) ISBN: 978-961-6187-67-1.

[19] Rajsman, Marijan. 2017. "Technology of Passengers Transportation in Road Traffic." Scientific book, Faculty of Transportation and Traffic Sciences, University in Zagreb, Croatia.

[20] Bowersox, Donald; Closs, David and Cooper, Bixby. 2010."Supply Chain Logistics Management." $3^{\text {rd }}$ edition. New York: McGraw Hill Irwin.

[21] Carić, Tonči. 2014. Optimization of traffic processes. Scientific book. Faculty of Transportation and Traffic Sciences, University in Zagreb, Croatia.

[22] Bokur, Zoltan. 2012. "Cost calculation model for logistics service providers." Promet - Traffic \& Transportation 24 (6): $515-524$.

[23] Bokur, Zoltan and Markovits-Somogy, Rita. 2015. "Improved Cost Management at Small and Medium-size Road Transport Companies: Case Hungary." Promet - Traffic\&Transportation 27 (5): 417-428.

[24] Kaukler, Vasja. 2011. "Search algorithms in a transit network of public transport and their implementation in GIS."Scientific book.. Faculty of Electrical Engineering and Computer Science. University of Maribor, Slovenia.

[25] Radačić, Željko. 2000. "Managing Complex Systems with a Special View of the Traffic System." Postgraduate Scientific Study, Authorised Lectures. Faculty of Transportation and Traffic Sciences, University of Zagreb, Croatia.

[26] Bubalo, Tomislav; Vojvodić, Hrvoje and Bokulić, Darko. 2015. "The exchange of data in the intercity bus traffic."In Proceedings of the 23rd Telecommunications Forum (TELFOR). Belgrade, (Serbia).

[27] Hensher, David and Button, Kenneth. 2001. Handbook of Transport Systems and Traffic Control. University of Sidney, George Mason University, Elsevier Science Ltd, Oxford, pp. 47-107.

[28] Šošić, Ivan and Serdar, Vladimir. 2002. "Introduction to Statistics.” School Book. Zagreb, pp. 79.-133.

[29] Statistical Reports. 2016. Transport and Communication /No. 37. Croatian Bureau of Statistics. Zagreb, 2017.

[30] Statistical Reports. 2018. Transport and Communication/Statistical Yearbook for the period 20092017. Croatian Bureau of Statistics. Zagreb, 2019.

[31] Statistical Reports. 2015. Transport and Communication / No. 15. Croatian Bureau of Statistics. Zagreb, 2016. 